\title{
Osteopontin - a multifunctional protein and its impact on an insulin resistance development
}

\author{
Katarzyna Musialik, Damian Skrypnik, Paweł Bogdański, Monika Szulińska \\ Department of Internal Diseases, Metabolic Disorders, and Hypertension, Poznan University of Medical Sciences, Poland
}

\begin{abstract}
Osteopontin (OPN) is one of the many physiological elements creating human musculoskeletal system. It is suspected that this protein is one of the most important mediators responsible for osseous tissue mass resorption, regulated by parthormon. The origin of its name comes from one of its physiological action - rebuilding of the bone mass structure (osteo - bone, pontin - bridge). Osteopontin fulfils many different actions being secreted by many different types of cells, including macrophages, lymphocytes, epithelial cells, vascular smooth muscle cells, and osteoblasts. OPN plays an important part in inflammatory process. It provokes macrophages and dendritic cells to movement into the destination where inflammatory process takes place. It also stimulates macrophages to interleukin 12 (IL12) and interferon Y (IFN Y) secretion. Increased OPN concentration in blood stream might be regarded as a novel, independent indicator of coronary artery disease. Osteopontin plays an important role in macrophage infiltration of the adipose tissue and at the same time contributes to insulin resistance. Obesity induces chronic, low-grade tissue inflammation. Positive correlation was observed between body mass index (BMI) and number of macrophages accumulated in the fat tissue. Once aroused monocytes infiltrate the adipose tissue, which leads to persisting chronic inflammation. At the same time the excreted by them cytokines may be connected with the mechanisms of obesity-induced insulin resistance.
\end{abstract}

Keywords: osteopontin, coronary artery disease, insulin resistance.

At the early beginnings of eighties in last century, osteopontin (OPN) was thought to be mainly associated with osseous tissue metabolism, particularly with its reconstruction. Later it started to be connected with neoplasms, probably because its chemotactic abilities and its elevated concentration in cancerous diseases. In $21^{\text {st }}$ century we are certainly sure that OPN is also involved in the development of obesity related diseases, such as type 2 diabetes, insulin resistance, and cardiovascular disorders.

For the first time in history osteopontin was described in 1979 as a fosfoprotein secreted by cancerous epithelial cells [1]. In scientific literature it occurs under different names, such as: Eta - 1 (early $\mathrm{T}$ lymphocyte activation protein 1) [2]; Spp1 (secreted phosphoprotein - I) [3]; 2ar [4] or uropontin [5].

The origin of its name comes from one of its physiological action - rebuilding of the bone mass structure (osteo - bone, pontin - bridge) [6]. OPN is one of the many physiological elements creating human musculoskeletal system. Its total amount constitutes $0.2 \%$ of whole bone mass [7]. OPN synthesis in skeletal system is controlled by calcitriol stimulation. It is suspected that this protein is one of the most important mediators responsible for osseous tissue mass resorption, regulated by parthormon (PTH) [8].

Osteopontin fulfils many different actions and it is why is a secreted by many different types of cells, including macrophages, lymphocytes, epithelial cells, vascular smooth muscle cells, and osteoblasts [9]. It has been proved that OPN is even involved in each part of phosphate urolith development [10]. OPN shows the capacity to adhere to the surface of target cells, what stimulates them to further migration. This protein was also classified as a T helper type 1 (Th1) stimulator [11]. 
OPN concentration is significantly higher in the cancer cells than in the healthy tissues, also its level grows proportionally to the malignancy and clinical stage of the neoplasm [12].

Osteopontin plays an important part in inflammatory process. It provokes macrophages and dendritic cells to movement into the destination where inflammatory process take place. It also stimulates macrophages to interleukin 12 (IL12) and interferon y (IFN Y) secretion [13]. OPN is being regarded as a proinflammatory protein. Others cytokines involved in inflammatory process such as: tumor necrosis factor - $\alpha$ (TNF - $\alpha$ ), transforming growth factor $-\beta$ (TGF $-\beta)$ and interleukin $1 \mathrm{~b}(\mathrm{IL}-$ $1 b)$ increase its synthesis [14]. At the same time osteopontin secretion might be stimulated by insufficient concentration of oxygen and hyperglycemia [15].

Simultaneously other authors proved that OPN also shows anti-inflammatory activity, by induction of nitric oxide synthase isoform (iNOS) to synthesis of nitric oxide (NO) in macrophages [16].

Nevertheless, vast majority of scientists regards OPN as an inflammation stimulating agent. To inflammationassociated diseases with elevated plasma level of osteopontin we can include: autoimmune diseases, Crohn disease, atherosclerosis, and of course obesity [17].

Nowadays, studies are being conducted on an osteopontin inhibitor. This potential molecule might be an agelastatin $A$. The performed in vivo trials on o group of patients with skin, breast and bladder cancer revealed promising effects. Osteopontin inhibitor slows down cancerous cell adhesion, invasion, and colony formation [18].

Beside traditional cardiovascular risk factors, increased OPN concentration in blood stream might be regarded as a novel, independent indicator of coronary artery disease [19]. Fitzpatrick et al showed high osteopontin concentration inside atherogenically changed blood vessel walls [20]. The total content of OPN in plasma may predict sustained VT/VF (ventricular tachycardia/ventricular fibrillation) in HF (heart failure) patients at high risk for SCD (sudden cardiac death). The combination of elevated OPN levels and high hsCRP levels (> $3 \mathrm{mg} / \mathrm{l}$ ) were significantly associated with increased risk of all-cause mortality, re-infarction and heart failure [21].

Experimental trials performed on rodents revealed elevated OPN levels in experimental diabetes mellitus [22]. There are also many other evidences suggesting OPN involvement in glucose homeostasis and keeping energy balance on the stable level. One of them is the fact that osteopontin deficiency in mice with obesity developed by overfeeding was associated with a 50\% reduction of macrophage infiltration in adipose tissue and improved insulin sensitivity [23].

Kiefer et al conducted study on C57BL/6J mice. The rodents were served a high-fat diet which leads to obesity. At the same time animals were receiving intravenous OPN-neutralizing antibodies. This method of treatment allowed to improve insulin sensitivity and decreased inflammatory process both in adipose tissue and liver. Anti-OPN therapy decreased expression of inflammatory gene by intensive macrophage apoptosis and reduction c-Jun NH2-terminal kinase activation. The influence of OPN neutralizing antibody leads to major improvement in insulin sensitivity in obese mice. The authors also observed that OPN is an important factor which regulates activation of hepatic signal transducer and is an activator of transcription 3 (STAT3). Blocked action of OPN induced decrease inflammation in adipose tissue. OPN concentration may be regarded as a novel link for obesity-related metabolic disorders treatment [24].

For obesity it is characteristic that massive macrophage infiltration is present in the fat tissue. Adipocytes - fat tissue cells produce excessive number of different kinds of cytokines, which is directly associated with insulin resistance and type 2 diabetes. Osteopontin plays an important role in macrophage infiltration of the adipose tissue and at the same time contributes to insulin resistance. Therefore it seems so important to understand the regulation of osteopontin expression by adipocytes. Well known, confirmed underlying mechanisms have not been yet established. There are multiple factors, including TLR4 (Toll-like receptor 4) activation induced by lipopolysaccharide (LPS) or palmitic acid, act in concert to up-regulate osteopontin expression by mononuclear cells through an IL-6-mediated mechanism.

Obesity induces chronic, low-grade tissue inflammation. Except of stimulated monocytes, and macrophages also adipocytes are actively involved in the secretion of proinflammatory cytokines. In case of obese individuals the levels of inflammatory markers such as highsensitivity C-reactive protein (hsCRP), tumor necrosis factor receptor (TNF - $\alpha$ ) or interleukin 6 (IL- 6 ) are consistently increased [25]. Those elements correlate positively with the risk of development cardiovascular diseases, and type 2 diabetes and insulin resistance [26]. Positive correlation was observed between body mass index (BMI) and number of macrophages accumulated in the fat tissue [16]. Once aroused monocytes infiltrate the adipose tissue, which leads to retaining chron- 
ic inflammation. At the same time secreted by them cytokines may be connected with the mechanisms of obesity-induced insulin resistance [27]. Increased OPN serum blood concentrations were found in the group of obese patients as compared with those with an appropriate weight [28].

As mentioned earlier OPN reveals great proinflammatory potential. It activates macrophages and dendritic cells. OPN also stimulates them to secretion of IL12, IFN $y$ and many other chemotactically active substances. They subsequently are able to increase insulin resistance. All these confirm the hypothesis that osteopontin might be the missing link between glucose intolerance and an obesity (as a low-grade chronic inflammation). Potential resolution of existing correlation between obesity and insulin intolerance might require knocking-down OPN genes or introducing into blood system its inhibitors. This will not only improve insulin sensitivity and help lose weight but it also could slow down tumor metastasis, cancerous cell adhesion and, prolong human live. Further investigations conducted in the future will bring us the correct answers.

\section{References}

1. Senger DR, Wirth DF, Haynes RO. Transformed mammalian cells secrete specific proteins and phosphoproteins. Cell. 1979;16:885-93.

2. Ishii T, Ohshima S, Ishida T, Kawase I, Mima T, Tabunoki $Y$, et al. Mice with osteopontin deletion remain predisponed to collagen-inducedarthritris. Arthritis Rheum. 2004; 50:669-71.

3. Wrana JL, Zang Q, Sodek J. Full lengh cDNA sequence of porcine secreted phosphoprotein-I (Spp-I, osteopontin). Nucleic Acid Res. 1989;17:10119-23.

4. Craig AM, Nemir M, Mukherjee BB, Chambers AF, Denhardt DT. Identification of the major phosphoprotein secreted by many rodent cell lines as 2ar/osteopontin: enhanced expression in $\mathrm{H}$-ras-transformed $3 \mathrm{~T} 3$ cells. Biochem Biophys Res Comm. 1988;157:166-73.

5. Shiraga H, Min W, VanDusen WJ, Clayman MD, Miner D, Terrell $\mathrm{CH}$, et al. Inhibition of calcium oxalate crystal growth in vitro by uropontin: another member of the aspartic acid-rich protein superfamily. Proc Natl Acad Sci. 1992;89:426-30.

6. Oldberg A, Franzen A, Heinega D. Cloning and sequence analysisof rat bone sialoprotein (osteopontin) CDNA reveals an Arg-Gly-Asp cell-binding sequence. Proc Natl Acad Sci. 1986;83:8819-23.

7. Reinholt FP, Hultenby K, Oldberg A, Heinegard D. Osteopontin - a possible anchor of osteoclasts to bone. Proc Natl Acad Sci. 1990;87:4473-5.

8. Ihara H, Denhardt DT, Furuya K, Yamashita T, Muguruma Y, Tsuji K, et al. Parathyroid hormone - induced bone resorption does not occur in the absence of osteopontin. J Biol Chem. 2001;276:13065-71.
9. Mazzali M, Kipari T, Ophascharoensuk V, Wesson J, Johnson R, Hughes J. Osteopontin - a molecule for all seasons. Q J Med. 2002;95:3-13.

10. Różański W, Klimek L, Jakubowski K, Miękoś E, Górkiewicz Z. Niekrystaliczne składniki kamieni moczowych. Urol Pol. 2003;56:7-10.

11. Gravallese EM. Osteopontin a bridge between bone and the immune system. J Clin Invest. 2003;112:147-9.

12. El-Tanani MK, Campbell FC, Kurisetty V, Jin D, McCann $M$, Rudland PS. The regulation and role of osteopontin in malignant transformation and cancer. Cytokine Growth Factor Rev. 2006;17:463-674.

13. Hullinger TG, Pan Q, Viswanathan $\mathrm{HL}$, Somerman MJ. TGF beta and BMP-2 activation of the OPN promoter: roles of smad- and hox-binding elements. Exp Cell Res. 2001;262:69-74.

14. Ashkar S, Weber GF, Panoutsakopoulou V, Eta-1 (osteopontin): an early component of type-1 (cell-mediated) immunity. Science. 2000;287:860-4.

15. Gomez-Ambrosi J, Catalan V, Ramirez B, Rodriguez A, Colina I, Silva $C$, et al. Plasma osteopontin levels and expression in adipose tissue are increased in obesity. J Clin Endocrinol Metab. 2007;92:3719-27.

16. Guo H, Cai CQ, Schroeder RA, Kuo PC. Osteopontin is a negative feedback regulator of nitric oxide synthesis in murine macrophages. J Immunol. 2001;166:1079-86.

17. Kiefer FW, Zeyda M, Todoric J, Huber J, Geyeregger R, Weichhart T, Aszmann O, Ludvik B, Silberhumer GR, Prager G, Stulnig TM. Osteopontin expression in human and murine obesity: extensive local up-regulation in adipose tissue but minimal systemic alterations. Endocrinology. 2008;149:1350-7.

18. Mason CK, McFarlane S, Johnston PG. Agelastatin A: a novel inhibitor of osteopontin-mediated adhesion, invasion, and colony formation. Mol Cancer Ther. 2008;7: 548-58.

19. Ohmori R, Momiyama Y, Taniguchi H, Takahashi R, Kusuhara $\mathrm{M}$, Nakamura $\mathrm{H}$, et al. Plasma osteopontin levels are associated with the presence and extent of coronary artery disease. Atherosclerosis. 2003;170:333-7.

20. Fitzpatrick LA, Severson A, Edwards WD, Ingram RT. Diffuse calcification in human coronary arteries. Association of osteopontin with atherosclerosis. J Clin Invest. 1994; 94:1597-604.

21. Bjerre M, Pedersen SH, Møgelvang R, Lindberg S, Jensen JS, Galatius $S$, et al. A.High osteopontin levels predict long-term outcome after STEMI and primary percutaneous coronary intervention. Eur J Prev Cardiol. 2013; 20:922-9.

22. Takemoto $M$, Yokote $K$, Nishimura M, Shigematsu $T$, Hasegawa T, Kon S, et al. Enhanced expression of osteopontin in human diabetic artery and analysis of its functional role in accelerated atherogenesis. Arterioscler Thromb Vasc Biol. 2000;20:624-8.

23. Nomiyama T, Perez-Tilve D, Ogawa D, Gizard F, Zhao Y, Heywood EB, et al. Osteopontin mediates obesity-induced adipose tissue macrophage infiltration and insulin resistance in mice. J Clin Invest. 2007;117:2877-88.

24. Kiefer F, Zeyda M, Gollinger K, Pfau B, Neuhofer A, Weichhart, et al. Neutralization of Osteopontin Inhibits Obesity-Induced Inflammation and Insulin Resistance. Diabetes. 2010;59:935-46. 
25. Samuvel DJ, Sundararaj KP, Li Y, Lopes-Virella MF, Huang Y. Interaction, Toll-like Receptor 4 Activation, and High Glucose Synergistically Up-regulate Osteopontin Expression via an Interleukin 6-mediated Mechanism J Biol Chem. 2010;285:3916-27.

26. Bogdański P, Musialik K. Metabolic syndrome - diagnosis and therapy. Lekarz. 2010;14:40-4.

27. Weisberg SP, McCann D, Desai M, Rosenbaum M, Leibel $\mathrm{RL}$, Ferrante AW Jr. Obesity is associated with macrophage accumulation in adipose tissue. J Clin Invest. 2003; 112:1796-08

28. Ahmad R, Al-Mass A, Al-Ghawas D, Shareif N, Zghoul N, Melhem $\mathrm{M}$, et al. Interaction of Osteopontin with IL-18 in Obese Individuals: Implications for Insulin Resistance. PLOS ONE 20.

\section{Correspondence address:} Katarzyna Musialik

Department of Internal Diseases, Metabolic Disorders, and Hypertension, Poznan University of Medical Sciences

84 Szamarzewskiego Street, 60-569 Poznań, Poland phone: +48 607299565 fax: +48618478529 email: kasia-musialik@wp.pl 